\title{
Insights into the magmatic processes, volatiles and environmental impacts through the life cycle of large igneous province volcanism
}

\author{
TAMSIN A. MATHER ${ }^{1}$, BEN BLACK ${ }^{2}$, LEIF \\ KARLSTROM $^{3}$, ANJA SCHMIDT ${ }^{4}$ AND LAWRENCE \\ PERCIVAL $^{5}$ \\ ${ }^{1}$ University of Oxford \\ ${ }^{2}$ City College of New York \\ ${ }^{3}$ University of Oregon \\ ${ }^{4}$ University of Cambridge \\ ${ }^{5}$ Vrije Universiteit Brussel \\ Presenting Author: tamsin.mather@earth.ox.ac.uk
}

Episodes of large igneous province (LIP) volcanism punctuate Earth history. LIPs are anomalous geologically rapid large-volume accumulations of igneous rock on the Earth's surface and in the shallow crust. Periods of LIP emplacement are often temporally associated with times of profound environmental and climatic change throughout Earth history. The fluxes of gas and particles emitted during LIP volcanism are key candidates for triggering these Earth system responses. Understanding these events-including feedbacks and impacts on the Earth system - requires collaboration between the fields of volcanology, atmospheric science, ocean chemistry, sedimentology and palaeobiology amongst others. This presentation will explore evidence constraining deep and shallow magmatic processes, volatile emissions, and the environmental impacts of LIP volcanism from disparate sources. Sources of evidence include: (1) province architecture, rock geochemistry and geodynamics; (2) temporal associations between the dates or proxies of LIPs and evidence of environmental change captured in the geological record; (3) historical records or monitoring studies of the effects of large-scale recent volcanic activity such as the Laki eruption in 1783-1784 CE and its deposits; and (4) scaling up from observations and measurements of the environmental impacts of present-day volcanism such as the 2014-2015 Holuhraun eruption and the 2018 Lower East Rift Zone eruption at Kīlauea, Hawai'i. Recent progress in each of these areas sets the scene for future advances in our understanding of these profoundly important events in Earth's history. 